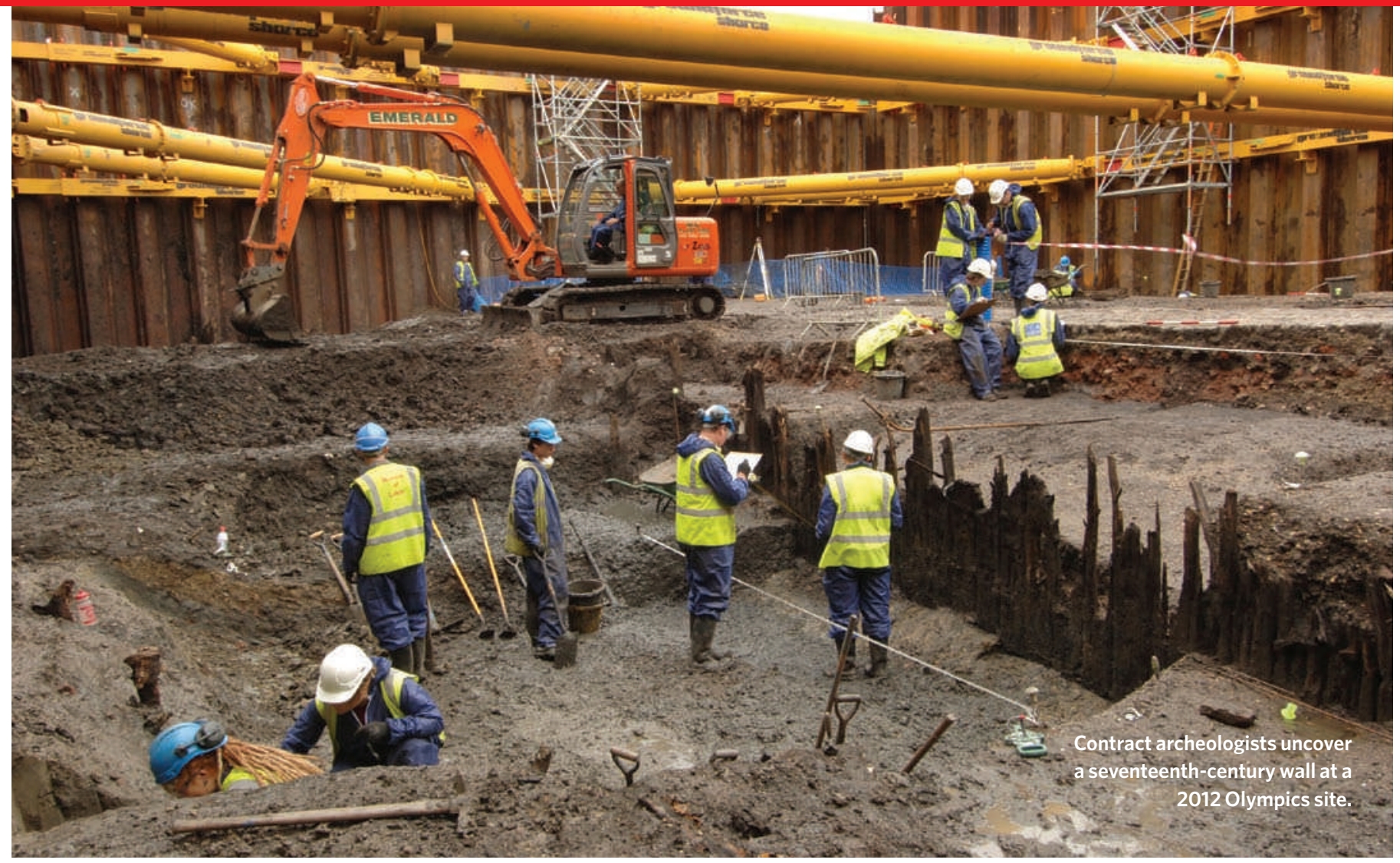

\title{
Hidden treasure
}

\section{The explosion in commercial archaeology has brought a flood of information. The problem now is figuring out how to find and use this unpublished literature, reports Matt Ford.}

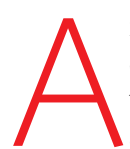
rchaeologists are used to gathering data by scratching in the dirt. But when Richard Bradley set out to write a new prehistory of Britain in 2004, he unearthed his most important finds while wearing sandals and a sweater rather than work boots and a hard hat.

Bradley is one of a growing number of academics in the United Kingdom who are doing their digging in the masses of unpublished 'grey literature' generated when commercial archaeologists are brought in to excavate before any sort of construction.

Bradley, a professor at the University of Reading, travelled around the country, visiting the offices of contract archaeological teams and local planning officials. There, he unearthed dozens of reports showing that settlements in England had remained strong during the Bronze Age and had not suffered a population crash, as academics had long thought.

"I became aware that what I was teaching would be out of date without looking at the grey literature," says Bradley.

For the past 20 years, Britain has been at the centre of a revolution in the funding and practice of archaeology. The shift was spurred by a 1990 change in policy that requires local governments to consider how construction projects will affect archaeological remains. That policy has essentially forced public and private entities to pay for archaeological assessments before they start laying a road, constructing an office building or engaging in other projects that disturb the ground.

In many ways the law has achieved its aim, helping to preserve relics that otherwise would have been destroyed. But at the same time, it has created problems for academics, who have struggled to keep up with the avalanche of new data, which some argue are hard to access.

Similar concerns have emerged in other countries that have enacted equivalent laws. But it's in the crowded British Isles - with its densely packed archaeological record and rapid pace of development - where the effect has been particularly profound.

"There is such a vast body of untapped stuff out there," says Barry Cunliffe, an emeritus professor of European archaeology at the University of Oxford. "This means there is a hold-up in academic development and the way in which the public are able to understand and appreciate archaeology."

The contractors disagree. Commercial work now accounts for $93 \%$ of the archaeologica research done in the United Kingdom, and academics must take note of the data generated by contract units, says Kenneth Aitchison, head of projects and professional development at the Institute for Archaeologists, the body representing commercial archaeologists in Britain. "This is the mainstream," he says. "The ones who complain are missing out."

Academic archaeologists are used to a system in which researchers conduct excavations and then publish their observations in monographs and journal articles, which are then available in libraries. But now the results of most excavations get written up for clients and local government planners, and are then held in private offices or local government buildings.

\section{Skeleton in the closet?}

Some academics, such as Bradley, are thankful for the new source of data and have responded by working more closely with commercial units. But others argue that fundamental changes are necessary to prevent market forces from letting down the archaeology.

"Where there is a real limitation is that the 
reports aren't necessarily publicly available," says Cunliffe. "It ought to be made mandatory that all these reports should be made available to the public. Sometimes a unit may say 'I'm sorry, my client is not prepared to make such and such a report public'”

Cunliffe says that his research, such as that on Iron Age Britain, has been affected by difficulties obtaining grey literature. Because these reports are not held in libraries, they are unavailable as inter-library loans, making it necessary to travel to read them.

"To go through all the records in all the units across the country would have taken years to do and just wasn't feasible in the context of writing a book," he says.

But that is where an increasing amount of archaeological information is stored (see 'Careers in ruins'). Statistics are limited, but it is estimated that in 2003-04, private developers sponsored the vast majority of UK archaeology, spending $£ 144$ million (US $\$ 220$ million), compared to around $£ 19$ million spent by the central government and the European Union, and around $£ 25$ million by local governments ${ }^{1}$.

\section{Knowledge is power}

Cunliffe's views are not unique. Another vocal critic has been Gary Lock, also at the University of Oxford. He wrote in the magazine British Archaeology in 2008 that while he was studying part of Oxfordshire, several developer-funded projects had been carried out nearby and he had been unable to access the reports. "Archaeological information is being treated as a commodity to which developers control access," he wrote ${ }^{2}$.

Even if academics can locate reports, that doesn't necessarily resolve all their concerns. "I know that some bits of grey literature I have seen are barely worth the paper they are printed on," says Cunliffe.

Commercial reports contain broadly the same sort of data as academic reports - interpretations of features, finds and chronology. But the reports are composed in response to planning, as opposed to research questions. There have also been complaints about the quality of some commercial archaeological work.

Representatives of that industry, however, argue that commercial units are advancing archaeology and that academics must keep pace. The grey literature, "does what it is supposed to do, and it is essentially accessible", says Aitchison.

Aitchison argues that the issue is not one of access, but rather of awareness, attitude and understanding. The major archaeological contractors - including Oxford Archaeology and Wessex Archaeology in Salisbury — are run as charitable trusts with educational aims. They forge links with universities and are working to get their grey literature online, says Aitchison. More material is published on the Internet than ever before, and the situation has improved massively in the past few years, he adds.

Laws requiring developers to fund archaeology operate to varying extents across Europe and North America, with similar debates taking place wherever they are applied.

"I reject the concept that grey literature is unpublished," says Deni Seymour, who worked in US contract archaeology for more than 25 years and for a decade co-ran the Lone Mountain Archaeological Services in Albuquerque, New Mexico. Grey literature, she says, "is no less available than many obscure journals and master's theses".

According to Seymour, "some academics and mainstream researchers think they are above looking at contract work and they don't

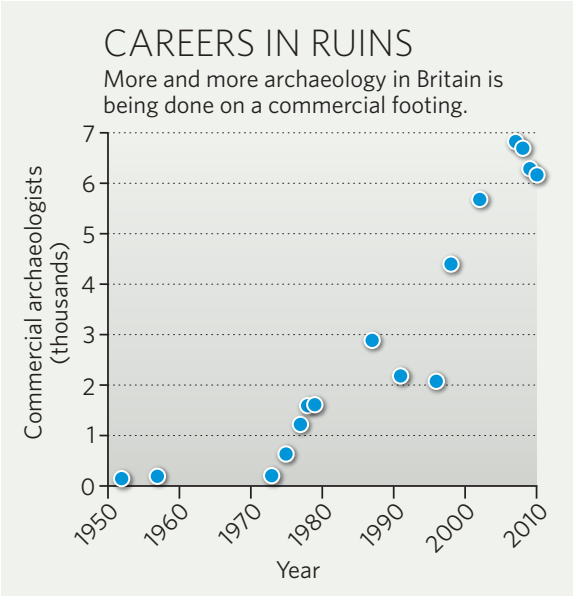

value it. In reality, I think many of them are five or more years behind with respect to new discoveries, concepts, method and theory."

Although opinions are strong on both sides about working practices and management issues, a consensus is emerging that grey literature contains important information and must be used.

"It is time for all scholars to engage their colleagues more widely and meaningfully, and to bridge the divide between the academic and the professional sectors," says Seymour, echoing many of her colleagues in and outside universities.

Ireland is showcasing a potential way to make the grey literature more easily available. A government-sponsored programme called Irish National Strategic Archaeological Research funds projects to synthesize grey data. In England, the Archaeological Data Service in York and Bournemouth University's Archaeological Investigations Project are working to put grey literature online. But finding money in the teeth of a recession, with UK universities already facing massive cuts, seems unlikely.

Academics who have dug into the grey literature say it can transform ideas about the past. Bradley's work, for example, turned the standard view of late Bronze Age Britain and Ireland on its head.

In the late 1980s, academics had concluded that the population in the British Isles had dropped markedly during the late Bronze Age. But since then, professional archaeologists have unearthed so many settlements from that period that "no one mentions a population decline any more", says Bradley.

\section{The other Roman Britain}

Michael Fulford, one of Bradley's colleagues at the University of Reading, has been piloting a study of the grey literature about Roman Britain, with similarly exciting results. "We've almost found 'another Roman Britain," he says, "one that we would have never seen without developer-funded archaeology."

Previously British Roman archaeology had tended to be biased towards excavating highstatus sites such as villas, as these were what researchers had chosen to investigate. But commercial excavations happen wherever developers are planning to break ground, and so provide a wider sampling of the past.

By embarking on a "massive photocopying campaign", Fulford assimilated huge amounts of data, representing a massive increase in both the number and type of sites now known. His study revealed the other side of Roman society. The low-status rural settlements showed how indigenous communities coexisted with Roman invaders, by keeping much of their vernacular architecture, but furnishing their homes with Roman manufactured goods. "A lot of the best work is coming out of commercial units now - a lot of the worst is as well, but you can say that about universities, quite frankly," says Fulford.

He advises PhD students who want to keep their hand in fieldwork that they might be better off working in commercial archaeology because it often involves large projects that are properly funded. "A lot of my contemporaries feel disenfranchised, but then that's too bad," says Fulford. "Despite the difficulties, we have to adapt to an archaeological record that is massively expanded and, at its best, of far better quality than has been achieved by academics, who are often very part-time fieldworkers."

\section{Matt Ford is a freelance writer in Bath, UK.}

1. Hinton, P. \& Jennings, D. in Quality Management in

Archaeology (eds Willems, W. J. H. \& van den Dries, M. H.) 100-112 (Oxbow, 2007).

2. Lock, G. Brit. Archaeol. 101, 36-37 (July/August 2008). 